\title{
Editorial
}

\section{Informal employment as a frontier of occupational safety and health research}

A large segment of workers worldwide have informal employment; that is, jobs that are "not subject to national labor legislation, income taxation, social protection or entitlement to certain employment benefits (advance notice of dismissal, severance pay, paid annual or sick leave, etc.)"1). The proportions are higher in developing and emerging countries (on average $60 \%$ of the workforce) ${ }^{1)}$; however, informal employment in developed countries is also substantial (currently about 17\%) ) $^{1)}$ because the formal economy strives to be flexible and competitive ${ }^{2)}$. These workers can be temporary or contract workers, day laborers, domestic workers, or have informal enterprises (e.g., street venders, Internet- or home-based sellers of goods or services). Although official statistics do not adequately capture occupational injuries and illnesses among these workers $^{3)}$, it is not hard to imagine that they are at higher risk for having poor working conditions that lead to poor health. In a recent Industrial Health editorial, Kawakami ${ }^{3)}$ called for the participatory, action-oriented training for those who are in the informal economy.

These hard-to-reach workers should be protected from known occupational hazards; however, we also need to address health risks associated with informal employment itself. In addition to the lack of training and protection, what specific features of informal employment are detrimental to health and safety? If informal and formal employees received the same training and performed the same tasks, would informal employees be still at higher risk for poor health? Would the uncertainty of informal employment harm workers? Are there subgroups of workers for whom informal employment is particularly harmful (e.g., depending on life stages, availability of social and family resources)? How do career trajectories develop for those in informal employment? Do they gain formal employment, or remain informal? What are the health implications of prolonged engagement in informal employment? How does the increasing presence of informal employees affect formal employees' health and well-being?

Addressing these questions requires broadening the traditional framework of occupational safety and health (OSH) research. Traditionally OSH research has focused on specific aspects of work (e.g., chemical exposure, ergonomic demands, work hours, task autonomy) and their associations with specific health outcomes (e.g., lung cancer, musculoskeletal disorder, obesity, depression). For this type of exposure-disease model to be useful, research focuses on workers who vary in exposure level but are otherwise relatively homogeneous. It is a common practice to remove from the study sample, for example, those whose job tenure is short or who are not directly employed by the employer (i.e., temp agency workers, subcontractors). Self-employed workers, some of whom may be informally employed, are often excluded from traditional OSH research as well. In order to study the health impacts of informal employment itself, we need a different approach that captures the complexity of today's workplaces.

Studying informal employment is difficult because such forms of employment are by definition ambiguous and unclear $^{2)}$. Worksite-based data collection, our traditional approach, may not be the most effective. Informal employment sites may be small in size, located in private homes, or not have a geographically-set place. Informal employees may be hesitant to participate in research studies for various reasons, including the vulnerability that stems from their employment relationship. Also, researchers may be reluctant to recruit them because it would be hard to retain them in a longitudinal study. However, these difficulties should encourage OSH researchers to be innovative. For example, qualitative research even on a small scale can be very powerful in discovering important aspects of informal employment.

Existing social surveys, which may not be designed for occupational research, can still offer information hard to gather elsewhere. A study by Ando et al. ${ }^{4)}$ demonstrates a creative use of multiple social surveys in investigating non-standard employment and cardiovascular risks. Other possible sources of data include coordinated working condition surveys conducted in European Union, United 
States, China, South Korea, and a number of Central and South American countries ${ }^{5)}$. Designed specifically to capture working conditions, the survey was administered as a population survey in each country and therefore able to capture informal employees. Although secondary data analysis has its disadvantages, exploring existing data is a worthwhile endeavor especially at an early stage of investigation. As we start paying closer attention to informal employment and its health implications, existing data may reveal more research opportunities than we initially expect, and the findings can refine future research directions.

OSH researchers can make significant contributions to the interdisciplinary effort of understanding the social and economic implications of informal employment. Various academic disciplines-e.g., economics, sociology, political science, anthropology, and gender studies-have recognized the importance of informal employment, not only as it has existed in developing countries but also as it emerges in developed countries as a new form of employment relationship ${ }^{2)}$. By proposing health, safety, and wellbeing as serious consequences of informal employment, OSH researchers can engage in this active interdisciplinary research and ultimately help deliver healthier and safer jobs to all workers.

\section{Disclaimer}

The contents of this editorial are solely the author's and do not necessarily represent the official position of the National Institute for Occupational Safety and Health, Centers for Disease Control and Prevention.

\section{References}

1) International Labour Organization (2018) Women and men in the informal economy: a statistical picture, 3rd Ed. International Labour Office, Geneva. https:/www.ilo.org/ global/publications/books/WCMS_626831/lang-en/index. htm.

2) Chen MA (2012) The informal economy: definitions, theories and policies (Vol. 1, No. 26, pp. 90141-4). WIEGO working Paper.

3) Kawakami $\mathrm{T}$ (2018) Reaching the unreached. Ind Health 56, 365-6. [Medline] [CrossRef]

4) Ando E, Kachi Y, Kawakami N, Fukuda Y, Kawada T (2018) Associations of non-standard employment with cardiovascular risk factors: findings from nationwide crosssectional studies in Japan. Ind Health 56, 336-45. [Medline] [CrossRef]

5) Eurofound and International Labour Organization (2019) Working conditions in a global perspective, Publications Office of the European Union, Luxembourg, and International Labour Organization, Geneva. https://www. ilo.org/global/publications/books/WCMS_696174/lang-en/ index.htm.

\section{Kaori FUJISHIRO}

Editor of Industrial Health

National Institute for Occupational Safety and Health (NIOSH) Centers for Disease Control and Prevention (CDC)

USA 